\title{
OXIDATION OF SECONDARY ALIPHATIC ALCOHOLS BY DIMETHYLDIOXIRANE: KINETICS AND SELECTIVITY
}

\author{
Mark A. Cunningham, P.C. Vasquez, Paul J. Franklin and A.L. Baumstark* \\ Department of Chemistry, Center of Biotechnology and Drug Design \\ Georgia State University, Atlanta, Georgia 30303-3083, USA
}

\begin{abstract}
The oxidation of acyclic (2-10) and cyclic (11-21) secondary aliphatic alcohols by dimethyldioxirane in acetone at $23^{\circ} \mathrm{C}$ produced the corresponding ketones in very good to excellent yields. Kinetic data ( $\mathrm{k}_{2}$ 's) were found to be similar for the acyclic series except for the most hindered compounds. The $k_{2}$ 's for the cyclic series were found to vary with ring size and to be generally larger than those for the acyclic cases.
\end{abstract}

\section{Introduction}

Dimethyldioxirane, 1 , is an oxidant of great utility due to its reactivity, versatility, selectivity, stereospecificity, convenience of preparation and effectiveness under mild conditions from commercially available material. ${ }^{1}$ These unique properties of 1 have afforded its use in a wide variety of useful transformations, ${ }^{1}$ including epoxidation, ${ }^{2}$ benzaldehyde oxidation, ${ }^{3}$ oxidation of acetals/ethers, ${ }^{4}$ heteroatom oxidation, ${ }^{5}$ oxidation of arenes, ${ }^{6}$ oxidation of secondary alcohols ${ }^{7}$ and carbon-hydrogen bond insertion. ${ }^{8}$ Mechanistic studies for the dimethyldioxirane oxidation of secondary alcohols are scarce and limited in scope. Studies of oxidation of $\alpha$-methylbenzylalcohols ${ }^{7 a}$ and several series of secondary alcohols and ethers ${ }^{7 b}$ by 1 have been reported. The reaction of 1 with diols has been shown ${ }^{9}$ to produce the corresponding hydroxy ketones. The reaction of methyl(trifluoromethyl)dioxirane, a more reactive dioxirane, with alcohols has been investigated extensively. ${ }^{10}$ We report here the results of a kinetic study of the dimethyldioxirane oxidation, in acetone, of a series of aliphatic cyclic and acyclic secondary alcohols to ketones.

\section{Results and Discussion}

The reaction of dimethyldioxirane 1 with 2-propanol 2, 2-butanol 3, 2-pentanol 4, 3-methyl-2-butanol 5, 3,3dimethyl-2-butanol 6, 3-pentanol 7, 3-hexanol 8, 4-heptanol 9, 2,4-dimethyl-3-pentanol 10, cyclobutanol 11, cyclopentanol 12, cyclohexanol 13, cycloheptanol 14, cyclooctanol 15, cyclodecanol 16, cyclododecanol 17, cis-4-tamylcyclohexanol 18, trans-4-t-amylcyclohexanol 19, endo-norborneol 20, and exo-norborneol 21 in acetone at $23^{\circ} \mathrm{C}$ produced the corresponding ketones in very good to excellent yields for all cases ( $\mathrm{rxn} 1)$. The ketones were the sole, observable products for all the oxidations. The products were characterized by GC/MS data and by comparison 


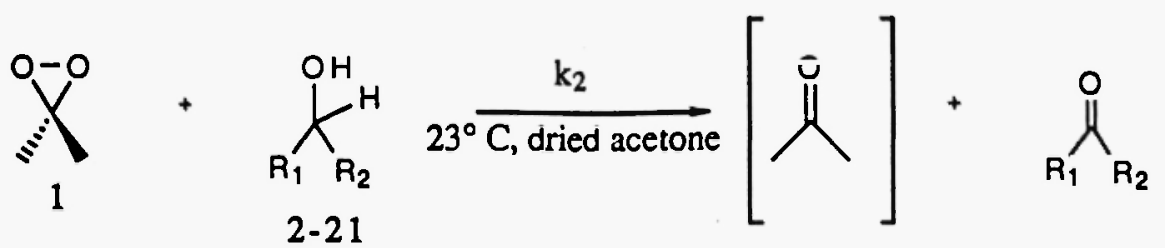

of spectral properties with authentic samples.

The oxidations are convenient and facile. An excess of 1 is required to obtain high conversions. For example, cyclooctanol $(0.0465 \mathrm{~g}, 0.36 \mathrm{mmol})$ was added to a stirred solution of $\sim 0.1 \mathrm{M}$ dimethyldioxirane ( 4 equivalents) in acetone 11 at $23^{\circ} \mathrm{C}$. Reaction progress was monitored by GC/MS. After disappearance of the alcohol ( $40 \mathrm{~min}$.), the acetone and excess dimethyldioxirane were removed under reduced pressure. The residue was extracted with methylene chloride and dried with magnesium sulfate. After evaporation of the methylene chloride, cyclooctanol $(0.032 \mathrm{~g}$, $0.33 \mathrm{mmol}$ ) was isolated in $92 \%$ yield. At least a 10 -fold excess of 1 and/or longer reaction times are necessary for efficient oxidation of acyclic alcohols and less reactive cyclic compounds.

Kinetic studies of the oxidation of 2-21 were carried out in acetone at $23^{\circ} \mathrm{C}$ employing UV techniques. The reactions were found to be of the second order overall. Excellent correlations were obtained for all experiments. The reactions were carried out under pseudo first order conditions with 1:10 and/or 10:1 alcoholdimethyldioxirane ratios which gave essentially identical $k_{2}$ values. The second-order rate constants for the acyclic and cyclic series are shown in Tables 1 and 2, respectively.

Table 1. Second-Order Rate Constants for the Oxidation of Acyclic Alcohols $\left(2-10, R_{1} R_{2} C H O H\right)$ by Dimethyldioxirane, 1 , in Dried Acetone at $23^{\circ} \mathrm{C}$.

\begin{tabular}{|c|c|c|c|c|}
\hline Compound & $\overline{\mathrm{A}_{1}}$ & $\mathrm{R}_{2}$ & $k_{2}\left(M^{-1} s^{-1}\right)$ & Rel. React. \\
\hline 2 & $\mathrm{Me}$ & $\mathrm{Me}$ & $1.69 \pm 0.05 \times 10^{-2}$ & $=1.00$ \\
\hline 3 & $\mathrm{Me}$ & Et & $1.49 \pm 0.01 \times 10^{-2}$ & 0.88 \\
\hline 4 & $\mathrm{Me}$ & $n-P r$ & $1.40 \pm 0.02 \times 10^{-2}$ & 0.83 \\
\hline 5 & $\mathrm{Me}$ & i-Pr & $1.44 \pm 0.05 \times 10^{-2}$ & 0.85 \\
\hline 6 & $\mathrm{Me}$ & $\mathrm{t}-\mathrm{Bu}$ & $1.42 \pm 0.03 \times 10^{-2}$ & 0.84 \\
\hline 7 & Et & Et & $1.31 \pm 0.05 \times 10^{-2}$ & 0.78 \\
\hline 8 & Et & $n-P r$ & $1.13 \pm 0.05 \times 10^{-2}$ & 0.67 \\
\hline 9 & $n-P r$ & $n-P r$ & $0.96 \pm 0.03 \times 10^{-2}$ & 0.57 \\
\hline 10 & i-Pr & $i-P r$ & $0.38 \pm 0.03 \times 10^{-2}$ & 0.22 \\
\hline
\end{tabular}

The second order rate constants for oxidation of acyclic secondary alcohols 2-6 are very similar although a slight decrease is observed as chain length increases. Increasing branching on the neighboring carbon as with alcohols 5 and 6 had little or no effect on the rate constants relative to those of the straight chain compounds. The most noticeable effect occurs when an alcohol is doubly beta-branched. Alcohol 10 undergoes oxidation approximately 3- to 5-fold slower than the other alcohols of the acyclic series. This suggests that the geometric requirements of the dioxirane/alpha proton interaction in the transition state are relatively insensitive to steric bulk. Branching on both sides, however, coupled to tree 
rotation, appears to interface sterically with the approach of 1 to the substrate. The slight relative rate decrease with increasing chain length (2-4, 7-8) can also be attributed to a similar steric effect since these longer chains are "floppy" due to free rotation which could retard approach of the reagent.

Second-order rate constants were determined for the oxidation of a series of cyclic secondary alcohols (see Table 2) by 1 . With the exceptions of 11,12 and 21 , the $k_{2}$ 's for the cyclic series are larger than those for the acyclic series. The $k_{2}$ values for 11-15 increased as ring size increased. A decrease in $k_{2}$ was observed for the 10-and 12-membered ring compounds, 16 and 17 . Conformationally restricted cyclic alcohols were also evaluated. The rate constants

Table 2. Second-Order Rate Constants for the Oxidation of Cyclic Alcohols, 11-21, by Dimethyldioxirane in Dried Acetone at $23^{\circ} \mathrm{C}$.

\begin{tabular}{|c|c|c|c|}
\hline Entry & Alcohol & $k_{2}\left(M^{-1} s^{-1}\right)$ & Rel. React. \\
\hline 11 & cyclobutanol & $0.57 \pm 0.1 \times 10^{-2}$ & 0.42 \\
\hline 12 & cyclopentanol & $1.35 \pm 0.02 \times 10^{-2}$ & $\equiv 1.00$ \\
\hline 13 & cyclohexanol & $3.5 \pm 0.1 \times 10^{-2}$ & 2.6 \\
\hline 14 & cycloheptanol & $5.9 \pm 0.1 \times 10^{-2}$ & 4.4 \\
\hline 15 & cyclooctanol & $6.4 \pm 0.1 \times 10^{-2}$ & 4.7 \\
\hline 16 & cyclodecanol & $5.2 \pm 0.2 \times 10^{-2}$ & 3.9 \\
\hline 17 & cyclododecanol & $2.40 \pm 0.06 \times 10^{-2}$ & 1.8 \\
\hline 18 & cis-4-t-amylcyclohexanol & $5.0 \pm 0.1 \times 10^{-2}$ & 3.7 \\
\hline 19 & trans-4-t-amylcyclohexanol & $3.3 \pm 0.1 \times 10^{-2}$ & 2.4 \\
\hline 20 & endo-norborneol & $4.4 \pm 0.1 \times 10^{-2}$ & 3.3 \\
\hline 21 & exo-norborneol & $0.54 \pm 0.05 \times 10^{-2}$ & 0.40 \\
\hline
\end{tabular}

of 18 and 19 differed, with the $\mathrm{k}_{2}$ for the cis isomer 1.5 times greater than that for the trans isomer. The $\mathrm{k}_{2}$ value for alcohol $\mathbf{2 0}$ was found to be $\mathbf{8}$ times faster than that for the exo isomer 21. The rate constants for the norborneol isomers are lower in magnitude and follow the same trend but with a smaller difference in relative rates than noted for the oxidation using methyl(trifluoromethyl)dioxirane. ${ }^{10}$ For the rigid cases shown here, the least stable alcohol has a greater rate constant. The least stable alcohol exposes the alpha-hydrogen to interaction with the oxidizing agent in the least sterically demanding position. Due to the similarity between the rate constants for 13 and 19 , it seems likely that the oxidation of 13 is proceeding via the most stable conformer with the hydroxyl group in the equatorial position. It is of interest to note that with the differences in rate constants between the acyclic and larger ring cyclic secondary alcohols, selectivity-biased toward the cyclic alcohol should be observed in a molecule containing both moieties. Further work to address this selectivity issue is in progress.

\section{Conclusion}

The oxidation of secondary aliphatic alcohols by dimethyldioxirane, in excess, produces high yields of ketones. Rate studies have shown differences in reactivity among acyclic and cyclic secondary alcohols which will be useful in 
designing selective oxidations. A particular point of interest is the environmental triendliness of dimethyldioxirane as opposed to using toxic heavy metals as oxidants.

Acknowledgment. Acknowledgment is made to the National Science Foundation (CHE-9017230), the U.S. Army ERDEC [Sensors, Energetics, Aerosols and Systems (SEAS) subcontract via CAU (DAAA 15-94-K-0004)] and the Georgia State University Research Fund for support of this work.

\section{References and Notes}

(1) For reviews see: a) R. Curci in "Advances in Oxygenated Processes" Vol. 2; A.L. Baumstark, Ed., JAI Press, Greenwich, CT 1990; b) R.W. Murray, Chem. Rev. 89, 1187 (1989); c) W. Adam, L.P. Hadjiarapoglou, R. Curci, R. Mello, Chapt. 4 in "Organic Peroxides"; W. Ando, Ed., Wiley and Sons, Chichester, England 1992.

(2) a) A.L. Baumstark, E. Michelena-Baez, A. Navarro and H.D. Banks, Heterocycl. Commun. 3, 393 (1997); b) J.K. Crandall and T. Reix, Tetrahedron Lett., 2513 (1994); c) A.L. Baumstark and D.B. Harden, Jr., J. Org. Chem. 58, 7615 (1993).

(3) A.L. Baumstark, M. Beeson and P.C. Vasquez, Tetrahedron Lett. 30, 5567 (1989).

(4) R. Curci, L. D'Accolti, M. Fiorentino, C. Fusco, W. Adam, M.E. González-Nunez, R. Mello, Tetrahedron Lett., 4225 (1992).

(5) a) R.W. Murray, R. Jeyaraman and L. Mohan, Tetrahedron Lett. 2335 (1986); b) W. Adam, D. Golsch, L. Hadjiarapoglou, A. Levai, C. Nemes and T. Patonay, Tetrahedron 46, 13113 (1994).

(6) a) R. Jeyaraman and R.W. Murray, J. Am. Chem. Soc. 106, 2462 (1984); b) D.R. Boyd, R.J.H. Davis, L. Hamilton, J.J. McCullough and H.P. Porter, J. Chem. Soc. Perkin Trans. 1, 2189 (1991); C) R.W. Murray, M. Singh and N.P. Rath, J. Org. Chem. 61, 7660 (1996).

(7) a) A.L. Baumstark and F. Kovac, Tetrahedron Lett. 875 (1994); b) A.L. Baumstark, F. Kovac and P.C. Vasquez, Can. J. Chem., submitted.

(8) a) R. Jeyaraman and R.W. Murray, J. Am. Chem. Soc. 106, 2462 (1984); b) G. Arsensio, R. Mello, M.E. GonzálezNunez, C. Boix and J. Royo, Tetrahedron Lett. 38, 2373 (1997); C) D. Kuck, A. Schuster, C. Fusco, M. Fiorentino and C. Curci, J. Am. Chem. Soc. 116, 2375 (1994).

(9) a) P. Bovvicelli, P. Lupattelli and A. Sanetti, Tetrahedron Lett. 3031 (1994); b) L. D'Accolti, A. Detomaso, C. Fusco, A. Rosa and R. Curci, J. Org. Chem. 58, 3600 (1993).

(10) a) R. Curci, M. Fiorentino, C. Fuseo and R. Mello, in Dioxygen Activation and Homogeneous Catalytic Oxidation, L.I. Simándi, Ed., Elsevier Science Publishers B.V., Amsterdam 1991, p. 147; b) W. Adam and L.P. Hadjiarapoglou, Top. Curr. Chem. 164, 45 (1993); c) R. Curci, A. Dinoi and M.F. Rubino, Pure Appl. Chem. 67, 811 (1995).

(11) Isolated dioxirane (0.06-0.1 M., dry in acetone) was prepared by a procedure that was an adaptation of the experimental approach of a) R.W. Murray and R.J. Jeyaraman, J. Org. Chem. 50, 2847 (1985); b) A.L. Baumstark and C.J. McCloskey, Tetrahedron Lett. 28, 3311 (1987); c) also see W. Adam, L. Hadjiarapolglou and J. Bialas, Chem. Ber. 124, 2377 (1991).

\section{Received on February 18, 1998}

